\title{
SISTEM PENUNJANG KEPUTUSAN PEMILIHAN VARIETAS JAGUNG BERDASARKAN KESESUAIAN LAHAN DENGAN METODE PROFILE MATCHING
}

\author{
Zaenuddin $^{1)}$, Mirza Yogy Kurniawan ${ }^{2)}$ \\ ${ }^{1}$ Fakultas Teknologi Informasi, Universitas Islam Kalimantan \\ Muhammad Arsyad Al Banjari Banjarmasin \\ Email: zaenuddin.uniska@gmail.com \\ ${ }^{1}$ Fakultas Teknologi Informasi, Universitas Islam Kalimantan \\ Muhammad Arsyad Al Banjari Banjarmasin \\ Email: mirza@fti.uniska-bjm.ac.id
}

\begin{abstract}
ABSTRAK
Produksi jagung dalam negeri masih bisa meningkat melalui perluasan areal tanam jagung utamanya di luar daerah jawa. Namun produktivitas meningkat, namun rata - rata produktivitas jagung nasional masih belum maksimal. Padahal teknologi produksi jagung semakin canggih.Potensi jagung di daerah Kalimantan selatan khususnya Kabupaten Tanah Laut terbilang sangat besar namun varietas yang ditanam belum sesuai dengan spesifikasi lahan yang dimiliki. Profile matching dapat memberikan rekomendasi berdasarkan variabel kesesuaian lahan dengan varietas.Sistem penunjang keputusan yang dihasilkan telah memiliki fitur yang dibutuhkan untuk merekomendasikan varietas jagung yang sesuai dengan lahan yang akan ditanami.
\end{abstract}

Kata Kunci : kesesuaian lahan, profile matching, sistem penunjang keputusan 


\section{PENDAHULUAN}

Peningkatan produksi jagung dalam negeri masih terbuka lebar baik melalui peningkatan produktivitas maupun perluasan areal tanam utamanya di luar Jawa. Meskipun produktivitas jagung meningkat, namun rata-rata tingkat produktivitas jagung nasional dari areal panen sekitar 3,60 juta hektar baru mencapai 3,40 t/ha. Kegiatan litbang jagung dari berbagai institusi baik pemerintah maupun swasta telah mampu menyediakan teknologi produksi jagung dengan tingkat produktivitas $4,0-9,0$ ton/ha, tergantung pada potensi lahan dan teknologi produksinya (Litbang Deptan, 2008).

Selama ini, sebagian besar petani hanya memperoleh informasi dan kemudian meyakininya, yang selanjutnya ingin mencoba menanam karena ketertarikannya pada potensi hasilnya yang tinggi. Petani belum mempertimbangkan kesesuaian lahan dengan varietas yang dipilih dan kemampuan yang dimiliki untuk menyediakan input yang diperlukan varietas tersebut agar dapat mencapai hasil sesuai dengan informasi yang diperolehnya. Hal ini menjadikan usahataninya kurang efisien dan bahkan nilai jual yang diperoleh cenderung rendah (Panikkai, 2009).

Selama ini, potensi jagung di BP3K Kabupaten Tanah Laut terbilang besar dengan luas lahan tanam yakni 4.344 ha. Namun produktivitas tanaman jagung masih rendah sekitar 5,43 ton per ha. Hal ini disebabkan karena jagung ditanam pada lahan yang tidak sesuai dengan varietas jagung dan berpotensi produktivitas yang rendah (Yudi, 2012).

Khairunnisa (2015) menyimpulkan bahwa profile matching sebagai model Sistem Pendukung Keputusan dapat membantu Kepala BKPP Kota Bima dalam merekomendasikan komoditas tanaman pangan yang cocok pada lahan tertentu. Menurut Wahyudi (2008) analisis profile matching merupakan proses perbandingan kompetensi individu kedalam kompetensi tertentu. Helen Joan Lawalata (2012) menggunakan profile matching untuk mengidentifikasi genus Isolat BAL penghasil senyawa antimikroba. Joko Triwibowo juga menggunakan profile matching untuk memprediksi kelayakan lokasi BTS.

\section{METODE PENELITIAN}

Sistem yang akan dibuat akan membantu petani untuk menentukan varietas yang sesuai dengan spesifikasi lahan yang ada. Spesifikasi lahan yang ada akan dijadikan patokan nilai untuk dihitung gapnya dengan spesifikasi lahan varietas jagung tertentu.

Pada metode profile matching gap terbesar adalah minus empat (-4) sedangkan gap nilai antara spesifikasi lahan yang ada dengan spesifikasi lahan varietas jagung bisa terjadi lebih dari 4, maka sebelum diterapkan profile matching perlu dilakukan penyesuaian pada data keduanya menjadi data berkelompok dengan metode statistik data berkelompok.

Profile Matching akan diterapkan pada nilai gap antara spesifikasi lahan yang ada dengan spesifikasi lahan varietas, dihitung sampe ditemukan data ranking, sehingga ranking tertinggi akan menjadi rekomendasi varietas yang paling diutamakan untuk dipilih.

Implementasi kedalam bentuk software aplikasi menggunakan metode incremental. Fitur aplikasi dibuat satu persatu berikut dengan pengujiannya, diawali dengan pembuatan fitur utama perhitungan rekomendasi profile matching yang menampilkan detail, dilanjutkan fitur perhitungan rekomendasi profile matching dengan tampilan sederhana, fitur menu utama untuk kontrol, fitur pengelolaan data master dan report, dan terakhir fitur login yang memisahkan user dengan admin.

\section{HASIL DAN PEMBAHASAN}

\subsection{Implementasi Perangkat Lunak}

Sistem Penunjang Keputusan yang dihasilkan berupa sebuah perangkat lunak yang mampu merekomendasikan varietas jagung yang sesuai dengan spesifikasi lahan yang dipilih oleh user pada sampel data spesifikasi lahan yang dipakai adalah data lahan tiap kecamatan dari Kabupaten Tanah Laut.

\subsection{Form Depan}

Form ini merupakan form yang awal mula ditampilkan oleh perangkat lunak. Pada form ini pengguna bisa memilih menu yang ingin ditampilkan dengan pilihan menu User atau menu Admin. Pilihan menu User akan membuka form rekomendasi sedangkan pilihan menu Admin akan membuka form login untuk menginput nama pengguna dan kata sandi 


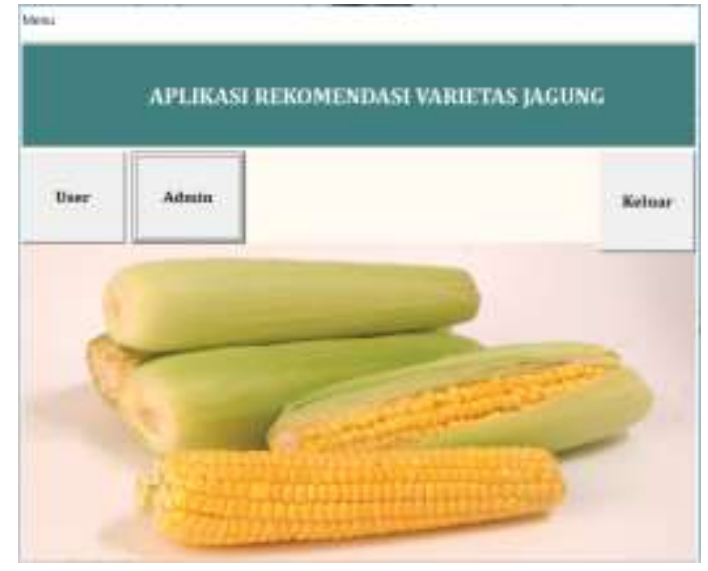

\subsection{Form Rekomendasi}

Form ini menampilkan fitur rekomendasi varietas yang mana bisa dipilih berdasarkan data desa dari Kecamatan Batu Ampar Kabupaten Tanah Laut ataupun berdasarkan inputan yang diinginkan user. Setelah dipilih dan diinput tombol Proses ditekan, maka akan menghasilkan rekomendasi varietas jagung dengan diurutkan dari yang paling cocok pada urutan teratas.

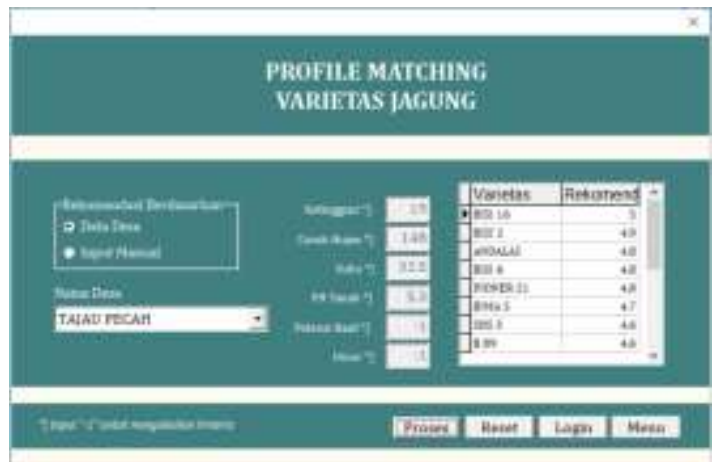

Gambar 1. Form Rekomendasi

\subsection{Form Batas Nilai}

Form ini digunakan untuk memberi batasan nilai agar data numerik dari spesifikasi lahan dapat dirubah menjadi data terkelompok dengan batasan nilai yang ditentukan dalam form ini.

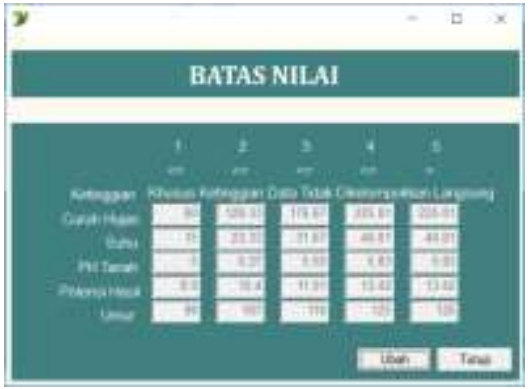

Gambar 2. Form Batas Nilai

\subsection{Form Proses Profile Matching}

Form ini digunakan untuk melakukan proses perhitungan profile matching antara spesifikasi lahan pada desa di Kecamatan Batu Ampar terhadap data varietas jagung. Tahapan perhitungan ditampilkan secara jelas dari pengolahan data menjadi data terkelompok, kemudian perhitungan gap-nya, bobot gap, core factor, secondary factor, hingga hasil nilai akhir. Pesan yang menunjukkan varietas yang direkomendasikan juga ditampilkan di akhir proses.

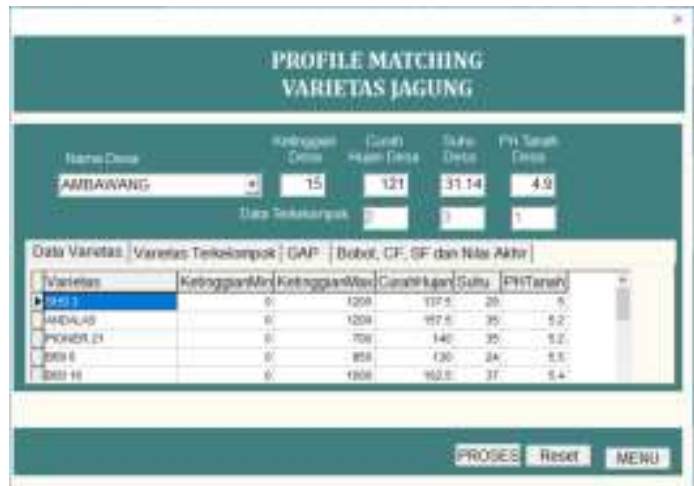

Gambar 3. Proses Profile Matching

\section{KESIMPULAN}

Sistem yang dihasilkan adalah sistem penunjang keputusan yang membantu pengguna untuk memilih varietas jagung berdasarkan spesifikasi lahan yang akan ditanami. Hasil pengujian black box kepada sistem menunjukkan bahwa fitur pada sistem sudah berjalan dengan baik. Hasil perhitungan metode profile matching dari sistem sudah sesuai ketika dibandingkan dengan hasil perhitungan manual 


\section{REFERENSI}

[1]. Khairunnisa. (2015). Sistem Pendukung Keputusan untuk Merekomendasikan Kesesuaian Lahan pada Komoditas Tanaman Prioritas dengan Metode Profile Matching dan AHP. Yogyakarta: Universitas Gadjah Mada .

[2]. Kusrini. (2007). Konsep dan Aplikasi Sistem Pendukung Keputusan. Yogyakarta: Andi Offset.

[3]. Panikkai, S. (2009). Penyebaran Varietas Unggul Jagung di Sulawesi Selatan. Prosiding Seminar Nasional Serealia, 509. 515.

[4]. Rostini, N. (2011). 6 Jurus Bertanam Cabai Bebas Hama dan Penyakit. AgroMedia Pustaka.

[5]. Singh, D., Thakur, A., \& Chaudhary, A. (2015). Comparative Study between Waterfall and Incrementan Software Development Life Cycle Model. International Journal of Emerging Trends in Science and Technology, 2202-2208.

[6]. Wahyudi, K. (2008). SISTEM PENDUKUNG KEPUTUSAN UNTUK PENEMPATAN JABATAN PADA CV. Prosiding Seminar Nasional Teknoin 2008, (hal. D-61 - D-65). Yogyakarta.

[7]. Yudi, M. R. (2012). SISTEM REKOMENDASI VARIETAS JAGUNG BERDASARKAN KESESUAIAN LAHAN MENGGUNAKAN FUZZY TAHANI. Banjarbaru: STMIK Banjarbaru.

[8]. Yusnita, H. D. (2010). Sistem Pendukung Keputusan Seleksi Sertifikasi Guru SD/MI oleh Kanwil Kemenag Propinsi Jatim Menggunakan Profile Matching. Surabaya: UPN "VETERAN" Jawa Timur.

[9]. Litbang Deptan. (2008). Buku Panduan Teknis Pengelolaan Tanaman Terpadu. Jakarta: Litbang Deptan. 